Spring 2018

\title{
Generativity and Other Buffers of Death Awareness in First Responders with PTSD
}

\author{
David Joseph Herr \\ Missouri State University, Herr316@live.missouristate.edu
}

As with any intellectual project, the content and views expressed in this thesis may be considered objectionable by some readers. However, this student-scholar's work has been judged to have academic value by the student's thesis committee members trained in the discipline. The content and views expressed in this thesis are those of the student-scholar and are not endorsed by Missouri State University, its Graduate College, or its employees.

Follow this and additional works at: https://bearworks.missouristate.edu/theses

Part of the Clinical Psychology Commons, and the Theory and Philosophy Commons

\section{Recommended Citation}

Herr, David Joseph, "Generativity and Other Buffers of Death Awareness in First Responders with PTSD" (2018). MSU Graduate Theses. 3277.

https://bearworks.missouristate.edu/theses/3277

This article or document was made available through BearWorks, the institutional repository of Missouri State University. The work contained in it may be protected by copyright and require permission of the copyright holder for reuse or redistribution.

For more information, please contact BearWorks@library.missouristate.edu. 


\title{
GENERATIVITY AND OTHER BUFFERS OF DEATH AWARENESS IN FIRST RESPONDERS WITH PTSD
}

\author{
A Masters Thesis \\ Presented to \\ The Graduate College of \\ Missouri State University
}

\author{
In Partial Fulfillment \\ Of the Requirements for the Degree \\ Master of Science, Psychology
}

By

David J. Herr

May 2018 
Copyright 2018 by David Joseph Herr 


\title{
GENERATIVITY AND OTHER BUFFERS OF DEATH AWARENESS IN FIRST \\ RESPONDERS WITH PTSD
}

Psychology

Missouri State University, May 2018

Master of Science

David J. Herr

\begin{abstract}
Anxiety buffer disruption theory (ABDT) is an application of terror management theory to posttraumatic stress disorder (PTSD). ABDT predicts that posttraumatic stress reactions occur when buffers of awareness of death, such as meaning in life, self-esteem, and social intimacy, fail to suppress overwhelming death-anxiety. The author suggested that generativity may also serve as an effective buffer of awareness of death. The present study investigated the presence of anxiety buffering disruption in first responders with PTSD via a mediation path model of self-report measures of PTSD symptoms, anxiety buffer variables, and death-though accessibility. While results indicate PTSD symptoms have a small relation to increased awareness of death, results indicate anxiety buffering variables account for an insignificant portion of the relation between PTSD symptoms and awareness of death. Nonetheless, generativity and meaning in life, self-esteem, and social support are significant predictors of lower levels of PTSD.
\end{abstract}

KEYWORDS: posttraumatic stress disorder, PTSD, generativity, anxiety buffer disruption theory, terror management, first responders

This abstract is approved as to form and content

Erin M. Buchanan, $\mathrm{PhD}$

Chairperson, Advisory Committee

Missouri State University 


\title{
GENERATIVITY AND OTHER BUFFERS OF DEATH AWARENESS IN FIRST RESPONDERS WITH PTSD
}

\author{
By \\ David J. Herr \\ A Masters Thesis
Submitted to the Graduate College
Of Missouri State University
In Partial Fulfillment of the Requirements
For the Degree of Master of Science, Psychology
}

May 2018

Approved:

Erin M. Buchanan, $\mathrm{PhD}$

William P. Deal, PhD

Ann D. Rost, $\mathrm{PhD}$

Julie Masterson, PhD: Dean, Graduate College

In the interest of academic freedom and the principle of free speech, approval of this thesis indicates the format is acceptable and meets the academic criteria for the discipline as determined by the faculty that constitute the thesis committee. The content and views expressed in this thesis are those of the studentscholar and are not endorsed by Missouri State University, its Graduate College, or its employees. 


\section{ACKNOWLEDGEMENTS}

I would like to thank Dr. Erin Buchanan who has led me through this process. I am grateful to have her as my thesis chair.

Given the subject matter of this thesis, I think it is most appropriate to dedicate it to two who were first responders following the most shocking disasters the world has known, who lived lives caring for others and pointing to the meaning of existence, and who faced their own deaths with upmost dignity:

Pedro Arrupe S.J. and Pat Malone S.J. 


\section{TABLE OF CONTENTS}

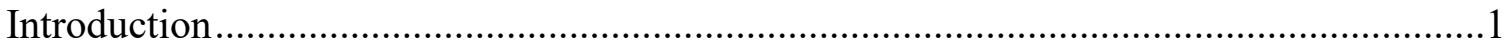

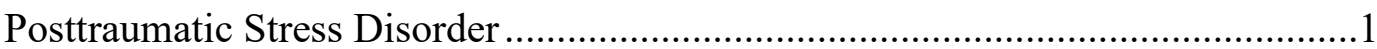

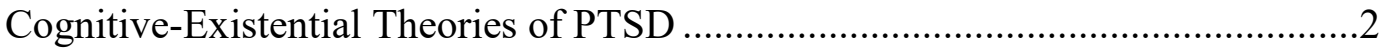

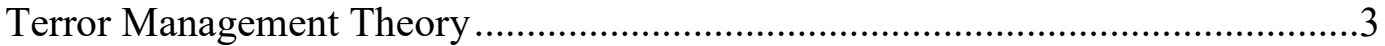

Anxiety Buffer Disruption Theory.................................................................

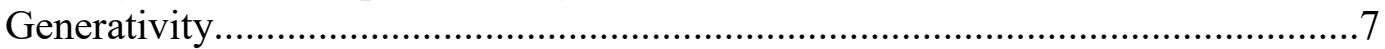

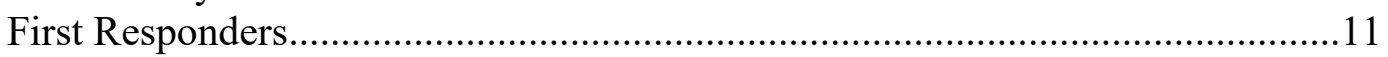

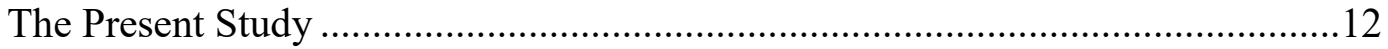

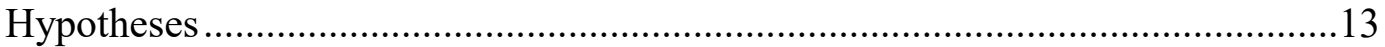

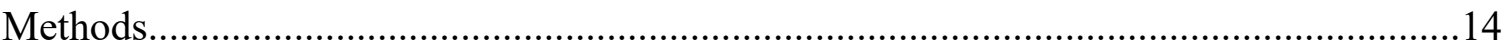

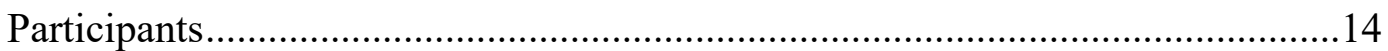

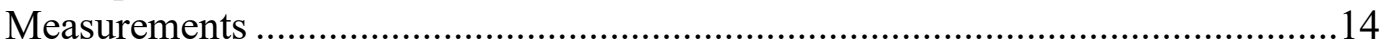

Abbreviated PTSD Checklist-Civilian Version .........................................14

Loyola Generativity Scale....................................................................15

Meaning in Life Questionnaire .............................................................15

Multidimensional Scale of Perceived Social Support................................16

Single-Item Self-Esteem Scale ………………………..........................16

Death-Thought Accessibility .................................................................16

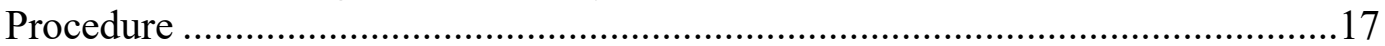

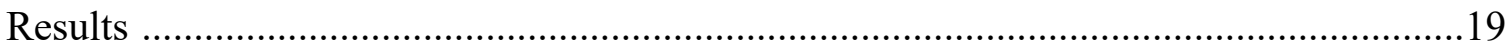

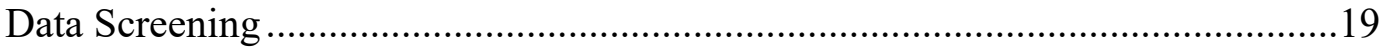

Responses to Mortality Salience Prompts.....................................................20

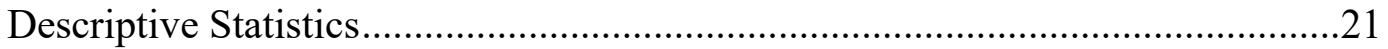

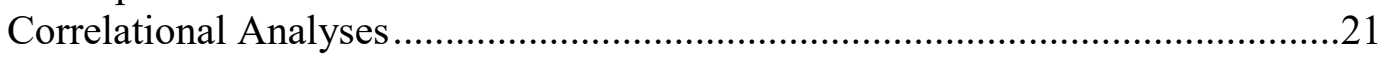

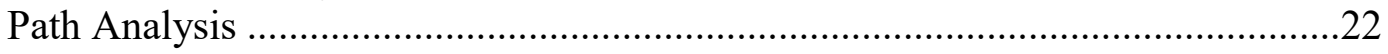

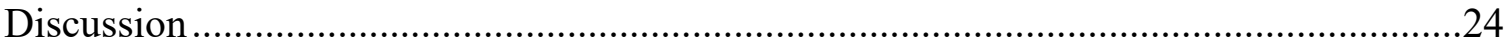

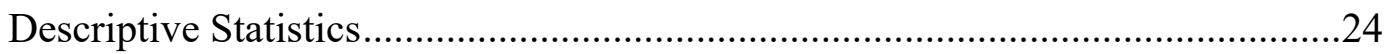

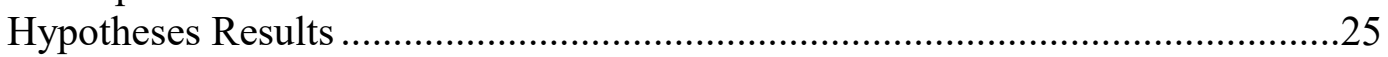

Responses to Mortality Salience Prompts.............................................................

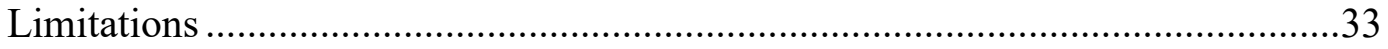

Summary

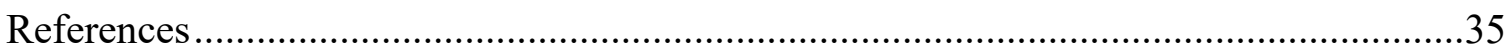

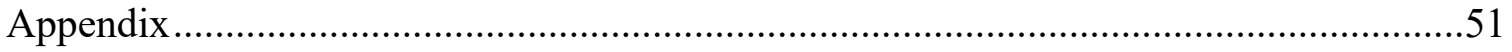




\section{LIST OF TABLES}

Table 1. Means and standard deviations of study variables........................................43

Table 2. Correlation of PTSD symptoms, anxiety buffer variables and DTA.................44

Table 3. Correlation of variables in control condition. ...............................................45

Table 4. Correlation of variables in mortality salience condition..................................46

Table 5. Parameter estimates for control condition. ....................................................47

Table 6. Parameter estimates for mortality salience condition. ...................................48 


\section{LIST OF FIGURES}

Figure 1. Path model of variables in control condition..............................................49

Figure 2. Path model of variables in mortality salience condition ................................50 


\section{INTRODUCTION}

\section{Posttraumatic Stress Disorder}

Posttraumatic stress disorder (PTSD) is psychiatric disorder characterized in the Diagnostic and Statistical Manual of Mental Disorders, Fifth Edition (DSM-5) by the presence of debilitating symptoms including intrusive memories and dreams, flashbacks, dissociation, avoidance, and negative alterations in cognition and mood after exposure to traumatic experience, including actual or threatened death, serious injury or sexual violence (American Psychiatric Association, 2013). The DSM-5 reports that using previous DSM-IV criteria, $8.7 \%$ of persons will have PTSD by the age of 75 , with higher rates among combat veterans, emergency first responders, refugees, and survivors of rape, natural disasters, and violent conflict (American Psychiatric Association, 2013; Ozer, Best, Lipsey \& Weiss, 2003). While the majority of persons experience a traumatic event in their lifetime, only a small fraction of these people develop PTSD (Ozer, et al., 2003). Several weak to moderate predictors of PTSD have been identified, including temperament, genetic factors and family mental health history, peritraumatic dissociation, and environmental factors (e.g. social support, coping strategies; American Psychiatric Association, 2013; Ozer et al., 2003 Weiss \& Ozer; 2006); however, it remains unclear how and why traumatic experiences lead to posttraumatic stress symptoms.

\section{Cognitive-Existential Theories of PTSD}

Various cognitive worldview theories propose posttraumatic stress reactions to occur due to the inability to accommodate traumatic experiences into held worldview 
schemas (Ozer \& Weiss, 2004). Shattered Assumption Theory (Janoff-Bulman, 1992) is one such theory which proposes traumatic events cause PTSD by violating positive assumptions/schema which provide a sense of security and coherence (e.g. The world is benevolent, predictable, meaningful; I am in control, worthy, etc.). Therefore, this discord causes cognitive dissonance, a sense of vulnerability to a dangerous and unpredictable world, and confusion.

There is evidence that traumatic experiences can cause a break-down of worldview assumptions and that such breakdown of worldview assumptions is aversive. Schuler and Boals (2016) measured assumptive worldview (the extent to which persons believe in the controllability of events, comprehensibility and predictability of people, trustworthiness and goodness of people, and safety of the world) using the World Assumptions Questionnaire (WAQ) on two occasions eight weeks apart, and found the presence of a traumatic event between the two times predicted a significant decrease in assumptive worldview between time two and one. The same study found assumptive worldview as measured by the WAQ also had moderate negative correlations with posttraumatic stress as measured by the PTSD Checklist-Specific $(r=-.35)$, depression, anxiety, and stress as measured by the Depression, Anxiety and Stress Scale $(r=-.34)$, and negative affect as measured by the Positive and Negative Affect Schedule $(r=-.37)$. Lilly, Howell, Valdez, and Graham-Bermann (2011) found worldview assumptions mediated the relationship between exposure to interpersonal violence and PTSD symptoms, suggesting that those with weaker worldview assumptions are more likely to develop PTSD from traumatic experiences. Belief and goal violations are positively related to levels of PTSD symptoms (Park, Mills \& Edmonson, 2012). 
Janoff-Bulman and McPherson Frantz (1997) suggest that positive worldview assumptions contribute to an overarching fundamental belief in a meaningful world. Violation of the belief in a meaning imbued world is aversive and contributes to negative cognitions and emotions. Similarly, other cognitive-existential theories suggest PTSD to be caused by traumatic events' discrepancy with held beliefs and meaning (including worldview assumptions) (Park \& Ai, 2006; Park, et al, 2012). Such theories posit distress to result from the disruption of the meaning-making process. There is ample evidence that one's sense of meaning in life is positively related to resiliency to trauma (and therefore lack of meaning is related to proneness to PTSD) (Alim et al., 2008; Aiena, Buchanan, Smith \& Schulenberg, 2016; Park et al., 2012), and that meaning-making is related to positive outcomes in persons with PTSD (posttraumatic growth) (Alim et al., 2008; Larner \& Blow, 2011; Kruger \& Swanepoel, 2017 Park 2013; Park \& Gutierrez 2013).

\section{Terror Management Theory}

Terror Management Theory (TMT) is an existential psychological theory in which meaning and worldview serve the specific purpose of suppressing death-anxiety. According to TMT, humans' unique cognitive capacities for self-awareness and forecasting future events cause us to be aware of the fact that we ourselves will die. Because of humans' evolved drive for survival, this awareness of our inevitable death causes death-anxiety and terror. If present, this terror would be paralyzingly distressing and dysfunctional, and in order to function, people must suppress this terror in ways 
which distract us from death, make us feel less vulnerable to death, or give us a sense of transcending death by being involved in symbols or transcending meaning.

The mortality salience (MS) hypothesis predicts increases in mortality salience (one's awareness of their inevitable death) causes a compensatory increase in attitudes and behaviors which push awareness of death out of consciousness and buffer aversive death-anxiety. The majority of TMT studies induce MS by having participants respond to two questions: "Please briefly describe the emotions that the thought of your own death arouses in you," and "Jot down, as specifically as you can, what you think will happen to you physically as you die and once you are physically dead" (Burke, Martens \& Faucher, 2010). Those in MS condition display significantly different levels of a wide variety of behaviors and attitudes which either distract from death, avoid physical death, or give a sense of symbolic immortality, including smoking or drinking significantly more, exercising more, donating significantly more, or asserting your cultural worldview by favoring ingroups and punishing or disparaging outgroups (Solomon, Greenberg \& Pyszczynski, 2015). Terror Management Theory research has found three primary ways we suppress death-anxiety: assertion in cultural worldview, self-esteem, and social intimacy. Data from a meta-analysis of 277 experiments indicates mortality salience to have moderate effects $(r=.35$; Burke, et al., 2010). The existential threat of awareness of one's inevitable mortality as induced by MS shows more effect on attitudes and behavior than other forms of harm, pain or uncertainty such as pain from dental work, giving public speeches, social rejection or taking a difficult exam (Burke et al., 2010; Solomon et al., 2015). 
Not only does mortality salience cause compensatory increases in affirmation of cultural worldview, social intimacy, and self-esteem, but, in what is referred to as the death-thought accessibility (DTA) paradigm, experimental reduction in these buffers causes an increased awareness of death (for a review of these studies see Hayes, Schimel, Faucher \& Arndt, 2010). Together, mortality salience studies and death-thought accessibility studies provide evidence of a dynamic relation between ever present deathanxiety and the buffers which suppress it.

\section{Anxiety Buffer Disruption Theory}

Anxiety Buffer Disruption Theory (ABDT; Pyszczynski \& Kesebir, 2011) is a sub-theory of TMT which posits that PTSD occurs when compensatory mechanisms of affirming cultural worldviews, close relationships, and self-esteem are not able to buffer against overwhelming death-anxiety. This unbuffered anxiety causes (or is) PTSD symptomatology.

One premise of ABDT is that unbuffered awareness of death causes aversive symptoms. The majority of TMT research has focused on compensatory behaviors which reduce awareness of death, therefore, little research has examined the negative emotional, psychological, and behavioral consequences that awareness of death is supposed to elicit when unbuffered. Of those which have, few have identified affect changes due to MS (Lambert, Scherer \& Slochower, 2014). A review of TMT literature by Lambert, Scherer and Slochower (2014) suggests the lack of affective response found is due to poor methodology, such as measuring anxiety rather than fear, or using measures not sensitive enough to detect differences between MS condition and other negative-affect inducing 
controls. The researchers' own series of four studies consistently show those in a MS condition have significantly greater fear, anxiety, and sadness, and significantly less happiness than those in a control condition. The authors posit fear to be the primary reaction to MS rather than anxiety, as when they controlled for fear, differences in other affects measured were reduced to insignificant levels. A small number of studies have found MS to harm psychological well-being of participants with low levels of anxiety buffering variables including meaning in life, interdependent self-construal (defining oneself in larger enduring social groups), and self-worth, by increasing death-anxiety and state anxiety, and decreasing vitality (defined as "aliveness and energy" considered an integral part of psychological well-being) (For a review, see Juhl \& Routledge, 2016).

Death-anxiety has been found to be related to a variety of mental disorders including anxiety disorders, panic disorder, phobias, depression, and, most relevant to our review, PTSD (for a review on death anxiety in various clinical populations see Iverach, Menzies \& Menzies, 2014; Maxfield, John \& Pyszczynski, 2014). Research on the relationship between death-anxiety and PTSD symptomotology lends support to ABDT. Hamama-Raz et al. (2016) found a significant moderate positive correlation $(r=.45)$ between death-anxiety and PTSD symptoms among Israeli adults, while Ron (2015) found a significant positive correlation between death-anxiety and PTSD symptoms among Phillepine migrants to Israel $(r=.51)$. Martz (2004) found death-anxiety to account for $12 \%$ of the variance in level of PTSD symptoms among persons with spinal cord injuries when controlling for demographic factors and disabilities.

Research has lent support to ABDT by finding evidence of a lack of anxiety buffering in persons with PTSD which is found in populations without PTSD. This has 
been done by finding compensatory death-denying mechanisms in response to MS in persons without PTSD but not in persons with PTSD or by finding increased DTA or negative emotional reaction following MS in persons with PTSD, but not in those without PTSD. For example, research has found MS to increase death-related thought accessibility in persons with high levels of war exposure and PTSD but not in persons with low levels war exposure and PTSD, suggesting the presence of a buffering mechanism in persons without PTSD but not in persons with PTSD (Chatard et al., 2012). Similarly, Edmondson, Chaudoir, Mills, Park, Holub and Bartkowiak (2011) found elevated DTA corresponding to PTSD symptom severity immediately following MS. Abdollahi, Pyszczynski, Maxfield and Luszczynska (2011) found persons with high levels of post-traumatic dissociation to show significantly lower levels of mortality salience effect (worldview defense: rejecting foreign aid, supporting conservative dress) than those with low levels of post-trauma dissociation, at both one month and two years following a devastating earthquake. In the same study, MS priming was associated with significantly lower positive affect among persons with high, but not low, PTSD symptomatology, suggesting the presence of anxiety buffering against MS among those with low PTSD, but not high PTSD. A study by Kesebir, Luszczynska, Pyszczynski, and Benight (2011) on domestic abuse victims in Poland, shows participants with PTSD do not display worldview defense that those without PTSD did.

\section{Generativity}

In addition to the buffers of cultural worldview/meaning, interpersonal intimacy, and self-esteem, we posit that generativity may serve as a buffer of awareness of death 
and death-anxiety, and therefore, PTSD symptoms. First coined by Erik Erikson in 1963 in The Life Cycle Completed, generativity can be defined in various ways including "care for the next generation," or "care for things which will outlast oneself” (Erikson, 1963/1998; McAdams, Hart \& Maruna, 1998). While generativity can be defined simply, it is a complex and multifaceted construct which derives from different motivations and can be expressed in multiple ways. Considering multiple theorists' work on generativity, McAdams and de St. Aubin (1992; retrieved in McAdams et al., 1998, p. 8) conceptualize generativity as being

"inner desire for agentic immortality and communal nurturance combined with age-graded societal norms experienced as cultural demand to produce in the adult years and increasing and more or less conscious concern for the next generation. Ideally generativity is reinforced by a belief in the goodness or worthwhileness of the human enterprise, generative concern leads to commitment, which, in turn, may produce action."

Generativity can be expressed in a variety of ways. Some examples include caring for things which outlast oneself through one-on-one interaction by parenting, teaching, or having friendships. On a larger social scale, persons can be generative through involvement in politics, social movements, or cultural endeavors. People might also care for personal projects which will be passed on to future generations such as creating art or contributing to science and technology.

Theorists and researchers have conceptualized generativity as being driven by two primary motivations, inner desire for immortality, and external cultural demand (McAdams et al., 1998). Drawing from Ernest Becker's The Denial of Death, which TMT was founded on, McAdams (1985) theorized that generativity is in part motivated by the need to create a self-defining legacy as an immortality project. Kotre (1984, p.10) 
puts even greater emphasis on generativity as death defying, defining generativity as "the desire to invest one's substance in forms of life and work that will outlive the self." Erikson himself (1963/1998, p. 66) introduces the stage of generativity versus stagnation with a story of a man experiencing the sense of urgency caused by an awareness of approaching certain death during middle life.

Generativity is related to the established buffers of death anxiety: assertion of cultural worldview/meaning, social intimacy, and self-esteem. Theorists conceptualize generative action as a form of meaning-making (McAdams \& de St. Aubin, 1992; Kotre, J. in de St. Aubin, McAdams, \& Kim, 2004, p. 35-50). Research showing evidence of a relationship between generativity and meaning support this claim. Lawford and Ramey (2015), have found generative concern among adolescents and young adults to predict meaning making $\left(r=.19\right.$ for adolescents ages $\left.M_{\text {age }}=17.2\right)$, and $r=.30$ for young adults $\left(M_{\text {age }}=20\right)$. Busch and Hofer (2012) found generativity and purpose in life to be strongly related $(r=.54)$, and Heintzelman, Trent and King (2016) found generativity significantly positively related to present meaning in life $(r=.57)$. Generativity has also been found to be related to self-esteem. For example, Bailey (1992 \& 1994) found generativity is significantly positively related to self-esteem in fathers $(r=.53)$ and mothers $(r=.40)$.

Generative action typically involves interpersonal engagement (e.g. raising children, teaching, caring for people), and social generativity is commonly culturally meaningful such as religious and political involvement (Cole \& Stewart, 1996; Singer, King, Green \& Barr, 2002). Hart, McAdams, Hirsch and Bauer (2001) found generativity to be positively correlated with social support from friends and family $(r=$ 
.30), involvement in religious activities such as attending religious services or praying, and political involvements such as voting, working for a political party or campaign, or contacting an elected official. Additionally, levels of generativity significantly positively correlate with how important participants believe politics are $(r=.24$ and $r=.23$ across two studies), likely because politics is a means of caring for future generations (Morselli \& Passini, 2015; Peterson, Smirles \& Wentworth, 1997). Generative actions often act as to serve a need for multiple death anxiety buffers. For example, as mentioned above, political and religious participation is a generative act which is both socially engaging and culturally meaningful (Cole \& Stewart, 1996; Singer, King, Green \& Barr, 2002). Raising children is a generative act which is an interpersonal endeavor, can be meaningful, and can increase self-esteem (Bailey, 1992; Bailey, 1994).

While generativity is theorized to be motivated out of a need for symbolic immortality, and research has related generativity to established death anxiety buffers of meaning in life, self-esteem, and social support, limited research has investigated generativity as a buffer of death-anxiety. Maxfield et al. (2014a) found mortality salience to increase generative concern among older adults, suggesting generativity serves an anxiety buffering function. Major, Whelton, Schimel and Sharpe (2016) found adults age 60-89 have significantly higher rates of reported generativity following a subtle MS induction than those who experience a blatant MS induction or controls. To our knowledge, no research has investigated the death-anxiety buffering effects of generativity in a non-elderly population. Within the framework of ABDT, generativity may serve as a protective function against the development of PTSD. 


\section{First Responders}

First responders include workers such as police, firefighters, and emergency medical technicians (EMT). First responders experience frequent exposure to traumatic events such as violence directed at them, being in dangerous and threatening situations, and witnessing harm to others. It is unsurprising then, that first respondents have higher rates of PTSD than the general population (American Psychiatric Association, 2013). Estimates of prevalence rates of PTSD in first responders vary widely, in part due to the use of different measures and cutoff scores (Del Ben, Scotti, Chen \& Fortson, 2006). A meta-analysis of 20,424 subjects from 40 samples by Berger and colleagues (2011) estimated rescue workers, including EMTs, firefighters, and police, to have a pooled point prevalence rate of PTSD of 10\%. Rates of PTSD between different types of first responders vary. Previous studies have found prevalence rates of PTSD in police officers varying between 7\% and 19\% (Mamar et al., 2006). Meta-analysis by Berger and colleagues (2011) found police recently exposed to a major disaster to have a PTSD point prevalence of $4.70 \%$. Prevalence rates of PTSD in firefighters have ranged from $5 \%$ to 37\% (Del Ben et al., 2006). Armstrong, Shakespeare-Finch and Shochet (2014) found $23 \%$ of their sample of firefighters had clinical levels of PTSD. Meta-analysis by Berger and colleagues (2011) found firefighters to have a PTSD point prevalence of $7.30 \%$. A literature review by Donnelly and Siebert (2009) suggests $82 \%$ to $100 \%$ of EMTs are exposed to trauma and estimate PTSD prevalence under 20\%. Meta-analysis by Berger et al. (2011) reports PTSD point prevalence in ambulance personnel at $14.60 \%$. Prior research has found higher rates of PTSD among EMTs than police officers, and firefighters possibly since EMT are exposed to more death. Ambulance personnel have 
higher rates of PTSD than firefighters who have higher rates than police exposed to trauma (Berger et al., 2011). EMTs also report higher rates of PTSD symptomatology than firefighters and police (Mamar et al., 2006).

Firefighters more commonly cite witnessing death as their most traumatic experience, rather than being in danger themselves. A study by Del Ben, Scotti, Chen and Fortson (2006) asked firefighters to name their "Single Worst Event." Seventy-two percent of respondents reported witnessing the death of another to be their worst event (death of an adult $38 \%$; death of a child $34 \%$ ), while $5 \%$ reported being injured or nearly killed as their worst event, although ratings of upset, fear, helplessness, and horror did not significantly differ between types of worst events. This finding is congruent with an existential theory of trauma in which trauma is caused by an awareness of one's inevitable death rather than actual or immediate threat to death.

\section{The Present Study}

The research at hand investigates the existential death-anxiety buffering effect of generativity, as well as previously established buffers of meaning, social support, and self-esteem by examining the moderating effects of generativity on mortality salience effects among persons with varying levels of post trauma. The research at hand will also examine generativity's relationship to the convergent constructs of meaning, social support, and self-esteem.

Previous ABDT research has conducted analyses by using null-hypothesis testing, typically by using factorial analysis of variance (ANOVA) to compare participants categorized as high or low PTSD symptoms, in MS conditions or control conditions. 
However, posttraumatic stress occurs on a spectrum. For this reason, the research at hand uses regression analyses via path modeling to analyze the relationship between PTSD symptoms, the mediating effect of proposed anxiety buffers and DTA. This analysis is advantageous because it retains power by using the entire continuum of each variable, thus, allowing for the examination of effects at every level of the variable. Previous ABDT research has found evidence of disruption of anxiety buffering and death-denying by finding evidence of lack of compensatory mechanisms, increased DTA and increased negative affect in persons with PTSD, but not those without following MS. Previously these different effects have been analyzed separately. By creating a path model and examining anxiety buffer's mediation of PTSD symptoms and DTA, we can estimate how much the relation between PTSD symptoms and DTA is due to varying levels of anxiety buffer variables.

\section{Hypotheses}

1) It is hypothesized generativity will be significantly positively correlated to present meaning in life, social support, and self-esteem.

2) It is hypothesized generativity, present meaning in life, social support, and selfesteem will be negatively correlated with PTSD symptoms.

3) It is hypothesized PTSD symptoms will be positively correlated with DTA in the MS condition but not in the control condition.

4) It is hypothesized generativity, meaning, social interaction, and self-esteem will mediate the relationship between PTSD symptoms and DTA in the MS condition stronger than in the control condition. 


\section{METHOD}

\section{Participants}

Participants $(N=986)$ were recruited online via a flyer advertising the research on multiple first responder groups and pages on Facebook.com. The Springfield, Missouri Police Department was also recruited for research participation via email. Participants were asked to share the link to the survey to any first responders or medical, police and fire departments they knew. Participants received entry in a raffle to win gift cards for participating. Mean participant age was $34.76(S D=12.05)$ The sample consisted of 542 males and 376 females. The sample included 864 participants who identified as White, 14 as Japanese, 10 as American Indian or Alaskan Native, 8 as Black or African American, 4 as Samoan, 3 as Vietnamese, 2 as Asian Indian, 2 as Korean, 2 as Guamanian or Chamorro, 1 as “Other Asian,” 1 as “Other Pacific Islander," and 1 as "Other.” 839 participants identified as not of Hispanic, Latino or Spanish origin, and 51 identified as Hispanic or Latino.

\section{Measurements}

Abbreviated PTSD Checklist - Civilian Version. The PTSD Checklist-Civilian Version (PCL-C) is a 17-item scale developed to measure PTSD symptomatology in nonmilitary populations (Weathers, Litz, Herman, Huska \& Keane, 1993). The PCL-C consists of 17 symptoms of PTSD such as "Repeated, disturbed memories, thoughts, or images of a stressful experience from the past?" or "Avoided activities or situations because they reminded you of a stressful experience from the past?" which participant 
rate according to how much it has been bothering them in the past month on a 1 to 5 scale from Not at all to Extremely. It is one of the most used and most psychometrically sound measures of PTSD (Gauci \& MacDonald, 2012). Abbreviated versions of the PCL-C exist in both a two and six item scales (Lang \& Stein, 2005). In the present study, we use the six-item Abbreviated PCL-C which is highly sensitive, has high internal reliability and is highly correlated with the full PCL-C (Lang \& Stein, 2005; Lang et al., 2012).

Loyola Generativity Scale. The Loyola Generativity Scale (LGS) is a 20-item self-report questionnaire in which participants rate how often the statements apply to them on a 0-3 scale from statement never applies to you to statement applies to you very often or nearly always (McAdams \& de St. Aubin, 1992). These statements are about one's care for others and things and include items such as "I feel as though I have made a difference to many people." Items 2, 5, 9, 13, 14 and 15 are reversed scored and all items summed for a total score of 0 to 60 . The LGS has high internal consistency and shortterm test-retest reliability. Consistent with Erikson's theoretical stages, persons in midlife score higher on the LGS than young adults and older adults. Overall, there are no significant gender differences in non-college samples.

Meaning in Life Questionnaire. The Meaning in Life Questionnaire (MLQ; Steger, Frazier, Oishi, \& Kaler, 2006) is a 10-item measure of both presence of meaning in life and search for meaning. The present meaning in life subscale is designed to measure the extent to which one feels their life has meaning and includes items such as "I understand my life's meaning," and "I have discovered a satisfying life purpose." The search for meaning in life subscale is designed to measure the extent to which one is searching for a life meaning and includes items such as "I am looking for something that 
makes my life feel meaningful." Each question is rated on a 1 to 7 scale from absolutely

untrue to absolutely true. The MLQ has been shown to have good internal consistency on both subscales.

Multidimensional Scale of Perceived Social Support. The Multidimensional Scale of Perceived Social Support (MSPSS) is a 12-item questionnaire in which participants rate how much they agree with statements about support from family, friends, and a significant other, such as "My family really tries to help me," and "I have friends with whom I share my joys and sorrows," on a 1 to 7 scale from very strongly disagree to very strongly agree (Zimet, Dahlem, Zimet \& Farley, 1988). Analysis of the MSPSS have found it to be psychometrically sound (Zimet, Powel, Farley, Werkman \& Berkoff, 1990; Canty-Mitchell \& Zimet, 2000).

Single-Item Self-Esteem Scale. The Single-Item Self-Esteem Scale consists of the item "I have high self-esteem," which participants rate on a Likert scale from 1 not very true of me to 7 very true of me (Robins, Hendin \& Trzensniewski, 2001). It has strong convergent validity and with the Rosenberg Self-Esteem Scale and similar predictive validity (Robins et al., 2001).

Death-Thought Accessibility. To measure death-thought accessibility (DTA), we used a word completion task retrieved from the TMT website (www.tmt.missouri.edu) which is often employed in TMT research (Greenberg, Pyszczynski, Solomon, Simon \& Breus, 1994; Hayes et al., 2010). Our word completion task included 25 incomplete words, six of which can be completed as either death related or neutral words (e.g. GRA _ can be completed as GRAVE or GRAPE, COFF__ can be completed as COFFIN or COFFEE, etc.), and 19 of which can only be completed with words unrelated to death. 
Participants are asked to complete the word fragments as quickly as possible with the first word which comes to mind. The DTA word completion is scored by adding the number of death related words completed, yielding a score of zero to six.

\section{Procedure}

All procedures were approved by the Missouri State University Institutional Review Board (IRB) before conducting the experiment (IRB-FY2017-754; approved on 06-14-2017). The experiment was conducted as approved by the IRB (see Appendix A for IRB approval documentation). Participants were recruited online to take a survey of consisting of the above mentioned measures and MS condition or control condition prompts on Qualtrics.com. We advertised the survey by sharing a survey flyer on multiple first responder pages on facebook.com. Participants filled out demographic information including age, gender, ethnicity, occupation (from which participants could choose between Firefighter, Emergency Medical Worker, Police, or Other with the option to write in their occupation), and workplace location (city and state). Participants then completed the LGS, Abbreviated PCL-C, MSPSS, MLQ, and Single-Item Self-Esteem Scale in randomized order. Participants were then randomly assigned to be in the MS or control condition. Participants of the MS condition where asked to respond to the questions "Please briefly describe the emotions that the thought of your own death arouses in you," and "Jot down, as specifically as you can, what you think will happen to you physically as you die and once you are physically dead." Participants in the control condition where asked to respond to the questions "Please briefly describe the emotions that the thought of having dental pain arouses in you," and "Jot down, as specifically as 
you can, what you think will happen to you as you experience dental pain.” All participants then completed the DTA word completion task. Upon completion of the survey, participants were informed of available mental health resources, and were asked for their contact information to be entered into a raffle to win one of twenty $\$ 25$ gift cards. 


\section{RESULTS}

\section{Data Screening}

986 participants responded to the online survey. 588 participants were found to have $5 \%$ or less of their data missing. Of those 588 participants, 584 had no missing data and 4 participants had one missing data point each; We imputed those four data points using R's mice package (van Buuren \& Groothuis-Oudshoorn, 2011). Next, we screened the data using procedures by Buchanan and Scofield (2018) to detect low quality data based on having low page timing as determined by characters per page, low click count, high number of scale options used, and uncommon data distributions. No participant's data were deemed to be low quality; therefore, no participant data were removed during this step.

Next, data we screened for multivariate outliers. Mahalanobis distances were calculated for each participant and compared to a chi-square cutoff of 85.35 (Tabachnick \& Fidell, 2007). Thirty-nine participants were removed from the data pool for having Mahalanobis distances greater than the chi-square cutoff. An additional 266 were removed during outlier screening for having greater than $5 \%$ of their data missing, leaving a remaining 681 participants. Of these 681 participants, all had completed the questionnaires presented before being exposed to conditions, and 592 had completed the entire survey, including the DTA word completion task. Of those who had completed the entire survey, there were 302 participants in the control group and 290 in the MS group. Data were screened for assumptions of additivity (i.e., no multicollinearity, $r>.90$ ), normality, linearity, homogeneity, and homoscedasticity. Data were found to be additive. 
A normal probability plot of multivariate residuals indicated the data were linear. The remaining data were found to be normally distributed and homoscedastic. Data were found to be slightly heterogeneous; however, due to the sufficient number of participants and robustness of analyses, we determined the data to be suitable for analyses.

\section{Responses to Mortality Salience Prompt}

Participant responses to MS prompts commonly included stating ways they cope with death, religious views, concern for their family, how their occupation influences their thoughts and feelings about death, and expressions of inability or unwillingness to think of their death. Responses to the prompt "Please briefly describe the emotions that the thought of your own death arouses in you," frequently included expressions of fear, including, "Scared. See it constantly, but when it comes to my health and my death, it terrifies me," "It makes me sad. I am so young and have such a long life ahead of me, but I feel as though I am going to die every single day. I have crippling anxiety and stress," and, "Every day I think of death almost like a countdown too it. There is a morose feeling that never ends. If I'm not helping someone I feel useless." Fewer responses expressed an acceptance towards death; "Honestly, it raises no emotions in me. It's a part of life," and, "My own death does not scare me in any way. With the work that I do and the work that I have seen, I am confident that I will go out of this world in a peaceful and controllable

manner." Many participants expressed generative concern, such as, "A thought of sadness comes to mind. I want to leave something behind other than a name and body. I'd like people to remember what I have done and how often I volunteer and how much I cared," and, "What contributions have I done in my life, in my family, and in my job?" 
Participants of the control group frequently wrote about the annoyance of having dental pain, and anxiety or unwillingness of going to the dentist.

\section{Descriptive Statistics}

Scores for each questionnaire and total death-related words produced in the DTA word completion task were calculated. Although not done in prior research, we counted fifteen responses of "noose" and one response of "corpse" as death words. Means and standard deviations for all research variables in all conditions can be found in Table 1.

\section{Correlational Analyses}

To test hypotheses 1, 2, and 3, correlations between all measures were calculated and are included in Table 2. Consistent with hypothesis 1, generativity was found to be significantly positively correlated to present meaning in life $(r=.60, p<.001)$, social support $(r=.43, p<.001)$, and self-esteem $(r=.47, p<.001)$. Consistent with hypothesis 2, PTSD symptoms were negatively correlated with proposed buffer variables of generativity $(r=-.28, p<.001)$, present meaning in life $(r=-.34, p<.001)$, social $\operatorname{support}(r=-.31, p<.001)$, and self-esteem $(r=-.35, p<.001)$.

It was hypothesized that PTSD symptomatology would be positively correlated with DTA in the MS condition but not in the control condition. Inconsistent with this hypothesis, PTSD symptoms were significantly positively correlated with DTA in both the MS condition $(r=.13, p=.03)$ and control condition $(r=.18, p=.002)$. For correlations between variables in control and MS condition, see Table 3 and 4, respectively. 


\section{Path Analysis}

We used R's lavaan package (Rosseel, 2012) and maximum likelihood estimation to create mediation models in both control and MS conditions. We defined a latent "anxiety buffer" variable with generativity, present meaning in life, social support, and self-esteem loading on to the variable. In our model, PTSD symptoms predicted DTA and the anxiety buffer. Anxiety buffer predicted DTA and mediated the relationship between PTSD symptoms and DTA. See Figures 1 and 2 to see model and loadings for control condition and MS condition respectively.

Generativity, present meaning in life, social support, and self-esteem, all significantly positively loaded on to the latent anxiety buffer variable in both control and MS conditions, indicating a strong relationship between these factors and the overall variable. Posttraumatic stress disorder symptoms positively predicted DTA significantly in the control condition $(\beta=.159, p=.015)$ but not in the MS condition $(\beta=.072, p=$ .268). PTSD symptoms negatively predicted anxiety buffer significantly in the control condition $(\beta=-.449, p<.001)$ and MS condition $(\beta=-.415, p<.001)$. Anxiety buffer did not predict DTA in the control condition $(\beta=-.048, p=.507)$ or in the MS condition $(\beta=$ $-.132, p=.068)$. Consistent with hypothesis 4 , anxiety buffer mediated the relationship between PTSD symptoms and DTA more strongly in the MS condition (indirect effect = $.055, p=.077$ ) than in the control condition (indirect effect $=.021, p=.509$ ). See Tables

5 and 6 to see parameter estimates for control condition and MS condition respectively.

The following fit indices were examined to determine model adequacy: $\chi^{2}$, Root Mean Square Residual (RMSEA: Steiger, 1990), Standardized Root Mean Residual 
(SRMR: Hu \& Bentler 1999), Normed Fit Index (NFI: Bentler \& Bonnett, 1980), TuckerLewis Index (TLI: Tucker \& Lewis, 1973), and the Comparative Fit Index (CFI: Bentler, 1990). Small values (<.06) are preferred for the RMSEA and SRMR indices, and high values closer to 1.0 indicate better fit for the NFI, TLI and CFI (Hu \& Bentler, 1999). Small $\chi^{2}$ values are preferred. Fit indices indicated exceptional model fit of both the control condition $\left(\chi^{2}=409.096, p<.001\right.$, RMSEA $=.06190 \%$ CI $[.019, .102]$, SRMR $=$ $.034, \mathrm{NFI}=.958, \mathrm{TLI}=.957, \mathrm{CFI}=.977)$, and MS condition $\left(\chi^{2}=385.872, p<.001\right.$, RMSEA $=.05490 \%$ CI $[.000, .097]$, SRMR $=.034, \mathrm{NFI}=.962, \mathrm{TLI}=.965, \mathrm{CFI}=.982)$. 


\section{DISCUSSION}

Anxiety buffer disruption theory (ABDT) posits posttraumatic stress disorder (PTSD) to be caused by an awareness of death which is not suppressed by the usual buffers of meaning in life/cultural worldview, social intimacy and self-esteem. We suggested that generativity may also serve as an effective anxiety buffer and therefore, may be related to lower levels of PTSD. Prior theory and research has indicated generativity, meaning in life, self-esteem, and social intimacy play a role in suppressing awareness of death. The present research investigated the disruption of anxiety buffering in persons with PTSD. To do this, we collected data of participants' levels of these anxiety buffering variables, as well as PTSD symptoms, and death-thought accessibility (DTA) following either mortality salience (MS) or a control.

\section{Descriptive Statistics}

Means of our sample's anxiety buffer variables were typical. Our sample's mean present meaning is life was slightly higher than previously established norms for the MLQ $(M=23.5, S D=6.6$ in Steger et al., 2006). Our sample mean self-esteem was slightly higher and had greater variability than norms for the Single-Item Self-Esteem Scale $(M=3.5, S D=1.1$, in Robins et al., 2001). Our sample mean social support was similar to those of previous studies (review of seven previous studies on the MSPSS included means ranging from 5.00 to 6.04 in Osman, Lamis, Freedenthal, Gutierrez \& McNaughton-Cassil, 2014). 
Participants had a mean Loyola Generativity Scale (LGS) score of $36.83(S D=$ 8.98). These scores are slightly lower than those found by McAdams and de St. Aubin (1992) (Male: $M=40.8, S D=7.9$; Female: $M=42.0, S D=7.0$ ). We find our sample's lower generativity rates unexpected. We might expect first responders to have higher levels of generativity than the general population, given their occupations involve care for others and saving lives, arguably one of the most effectively generative acts. It is possible our sample's slightly lower levels of generativity occurred because the types of generativity expressed in first responders is less well represented by the items of the LGS which cover topics of passing on knowledge, being remembered, being creative, and being productive (McAdams \& de St. Aubin, 1992).

A score of 14 or higher on the Abbreviated PCL-C indicates clinically significant post-trauma symptoms (Lang \& Stein, 2005). Using this cutoff, roughly half of participants reported clinically significant levels of PTSD symptoms. Our sample's rate of clinically significant PTSD symptoms was much higher than previous research, which used PTSD measures and clinically significant cutoffs to estimate PTSD prevalence rates. Prior research using this method have found PTSD rates in first responders ranging from $5 \%$ to $37 \%$ with metanalysis indicating a $10 \%$ PTSD prevalence (Del Ben et al., 2006; Berger et al., 2011).

\section{Hypotheses Results}

Anxiety buffer disruption theory (ABDT) conceptualizes PTSD as being caused by an awareness of death which is not suppressed by the usual buffers of meaning in life/ cultural worldview, self-esteem, and intimate social relations. In addition to these buffers, 
we suggested generativity may serve as an effective death-defying buffer. The present data and analyses provide partial evidence in support of ABDT, as explored through correlational analyses and a structural mediation model. Prior ABDT research shows evidence of disrupted anxiety buffering functioning by showing a lack of compensatory reactions in response to mortality salience in persons high in PTSD symptoms, as well finding increased DTA in persons with high levels of PTSD but not low levels of PTSD following MS and death priming (Pyszczynski \& Taylor; 2016). These two different types of evidence of disrupted anxiety buffering functioning have not been analyzed together. In creating a mediation model analyzing these three components together, we were able to estimate the extent to which disruption of anxiety buffer variables accounts for the relation between PTSD symptoms and DTA. According to the present data and analyses, disrupted anxiety buffering is a small and insignificant component of posttraumatic stress.

We hypothesized generativity would significantly correlate with other proposed anxiety buffer variables of present meaning in life, self-esteem and social support. Generativity was significantly correlated with all other anxiety buffer variables. This result was consistent with theoretical conceptualizations of generativity (McAdams \& de St. Aubin, 1992), as well as prior research relating generativity to meaning (Lawford \& Ramey, 2015; Busch \& Hofer, 2012; Heintzelman, Trent \& King, 2016), self-esteem (Bailey, 1992; Bailey 1994), and social support (Hart et al., 2001). Generativity and present meaning in life had the strongest correlation of any two measures across conditions $(r=.60)$ with $36 \%$ shared variance between the two variables. This result was consistent with seminal theoretical work on both generativity and meaning in life. 
McAdams and de St. Aubin (1992) conceptualize all components of generativity from motivational sources, thoughts, plans, and behavior to provide a sense of meaning. Frankl (1956/2006) identifies one's contributions to the world, such as being creative and helping of others, as one of three sources of meaning in life.

Present meaning in life was the highest loading variable on the latent anxiety buffer in both control and MS conditions, indicating it has the strongest relation to the overall variable. Meaning in life had similar correlations to social support and self-esteem as generativity. We have presented rational for why generativity is related to the other anxiety buffer variables; Present meaning in life also has a similar relation to social support and self-esteem. Indeed, social intimacy is a prominent source of meaning in life and having a meaning/purpose in life is a component of one's self-esteem.

We hypothesized PTSD symptoms would be significantly negatively related to anxiety buffer variables of generativity, present meaning in life, self-esteem, and social support. Consistent with this hypothesis, there was a moderate negative relationship between PTSD symptoms and the latent anxiety buffer variable in both control and MS conditions. Likewise, PTSD symptoms was significantly negatively related to all anxiety buffer variables individually (see Table 2). Our finding was consistent with previous research demonstrating PTSD symptoms to be negatively related to meaning in life (Alim et al., 2008; Aiena et al., 2016), self-esteem (Weinberg, 2013; Zhou, Wu \& Zhen, 2018), and social support (Marmar et al., 2006; Donnelly \& Siebert, 2009; Berger et al., 2011; Farnsworth \& Sewell, 2011). Generativity was of unique interest to our research. Only one prior study has investigated generativity and posttraumatic growth (Bellizzi, 2004). 
The present study is the first to examine generativity and PTSD symptom severity. As hypothesized, generativity was significantly related to lower levels of PTSD symptoms.

Alone, this relation between PTSD and lower levels of the anxiety buffer variables does not provide robust evidence of a disturbance in death-anxiety buffering mechanisms. While it is possible that lower levels of the anxiety buffer variable contribute to the development of PTSD, correlation alone does not indicate the relation to be due to a death-denying function of the variables. Greater evidence of anxiety buffer disruption in persons with PTSD can be found through MS and DTA paradigms. Specifically, following an increased awareness of death, persons with greater levels of PTSD should have increased awareness of death, while persons without PTSD who theoretically have intact death-anxiety buffering mechanisms should not see an increase in DTA.

To test this hypothesis, we used the combination of mortality salience (MS) and death-thought accessibility (DTA) paradigm used in previous ABDT research, in which we subjected participants to MS conditioning or a control and then measured DTA with a word completion task. We hypothesized PTSD would be significantly positively correlated to DTA in the MS condition as greater PTSD symptoms should indicate greater disturbance in death anxiety buffering, but not in the control condition in which participants, regardless of level of trauma should not have an unelevated awareness of death. Inconsistent with this hypothesis, our analyses found small significant positive relationships between PSTD symptoms and DTA in both the MS condition and control condition. Such a finding is difficult to explain, as it suggests a relationship between the presence of PTSD and increased awareness of death, though not specifically following 
reminders of death. In fact, our analyses indicate a stronger relation between PTSD symptoms and DTA in the control condition than in the MS condition (See Tables 3 and 4).

Comparison of path models of the MS and control condition indicates a greater role of anxiety buffer variables in suppressing DTA in the MS than in the control condition. We expected the anxiety buffer to mediate the relationship between PTSD symptoms and DTA, that is, we expected that the varying presence and absence of the anxiety buffer was the underlying mechanism of the relationship between PTSD symptoms and increased death-awareness. We hypothesized the mediation to be stronger in the MS condition than the control condition. Consistent with our hypothesis, the mediation was stronger in the MS condition than in the control condition. The mediation was, however, not statistically significant in either condition. Also, the anxiety buffer variable more strongly predicted DTA in the MS condition than the control condition, suggesting a stronger role of the anxiety buffer in suppressing death-awareness when mortality was made salient.

PTSD significantly predicted DTA in both MS and control condition, suggesting an increased activation of death thoughts in persons with higher levels of PTSD, though not necessarily in reaction to MS. On the other hand, the stronger mediation and relation between anxiety buffer and DTA in the MS condition than control condition does suggest a that anxiety buffers played a greater role in suppressing awareness of death in the MS condition than in the control, suggesting an anxiety buffering reaction to MS. These two findings give conflicting evidence of the presence of anxiety buffer disruption. 
A possible explanation that can explain both findings is that all participants' awareness of death were inadvertently increased prior to taking our DTA measure. There are a few ways participants of both groups may have been primed with thoughts of death. Mortality may have been made salient by administration of the LGS. Three items of the LGS contain the word "die" and ask participants to reflect on their death ("I think that I will be remembered for a long time after I die.", "I feel that I have done nothing that will survive after I die.", and "I feel as though my contributions will exist after I die."). One prior study eliminated this death-priming effect by removing the word "die" from these items (Williams, Whelton, Schimel \& Sharpe, 2016); however, we decided to keep the scale intact, so as not to change the psychometric properties of the LGS. Future research might use a reduced item version of the LGS (Einolf, 2014) which does not contain items related to death to avoid this possible confound when studying generativity under TMT paradigms.

It is also possible that participants of both groups were primed with awareness of their trauma prior to taking the survey. In addition to a MS and control group, prior ABDT research has included conditions in which participants are asked to think about their traumatic experience (e.g., earthquake salience) but not death specifically (Pyszczynski \& Kesebir, 2011). Such trauma salience conditioning has been found to have similar effects as mortality salience conditioning among participants with trauma (Abdollahi et al., 2011). Our sample may have inadvertently been primed with thoughts of their trauma. All participants filled out the Abbreviated PCL-C prior to completing the DTA word completion task causing those with posttraumatic symptoms to reflect on their symptoms. Participants who took the survey after seeing it advertised on Facebook.com 
first responder groups and pages had likely been scrolling through Facebook.com feeds and walls which included reminders of their first responder occupation, presumably the source of most participants' traumatic experiences. The flyer and informed consent page, by describing the research as studying stress in first responders may have primed participants with an awareness of their occupation as related to stress, which for many participants may involve occupation related posttraumatic stress and frequent witnessing of death or threat of death.

DTA paradigm studies typically show that increase in DTA following MS is greatest when a time delay or task-switching is employed between the MS/death prime and the DTA measure (Hayes et al., 2010; Steinman \& Updegraff, 2015). It is possible the control conditioning (answering prompts about dental pain) may have acted as a delay between MS/death-priming and DTA measure, causing activation of death to increase (Greenberg et al., 1994; Hayes et al., 2010).

While participants of both groups may have been primed with death or deathrelated traumatic experiences, participants of the MS group would have had mortality made more salient to them than the control group. Participants of the MS group also completed the DTA immediately following mortality salience, while participants in the control group, by spending time answering the control condition prompts about dental pain, had a delay and distraction between their potential increased awareness of death or trauma, and the DTA word completion task. With greater activation of death in the MS condition, and without delay or opportunity for distraction, the role of the anxiety buffer variables in suppressing awareness of death may have been greater. This might account 
for the stronger relationship between anxiety buffer and DTA in the MS condition than in the control condition.

It is also possible that the significant positive relation between PTSD and DTA occurring in both groups reflects an increased awareness of death corresponding to levels of persistent posttraumatic stress. This explanation seems plausible and would be consistent with TMT which describes awareness death as an ever-present threat. Even without the theoretical framework of TMT, it is intuitive that persons with higher levels of posttraumatic stress have generally higher cognitive activation of death. However, both of these explanations do not account for equivocal death-word totals across groups (see Table 1). In all cases, both correlations between variables and DTA and paths relating to DTA in our models were small. While we found evidence of disrupted anxiety buffering corresponding to PTSD symptoms, the present study suggested disrupted anxiety buffering function was only a small and insignificant component of posttraumatic stress.

\section{Responses to Mortality Salience Prompts}

Participant responses to MS prompts commonly included stating ways they cope with death, religious views, concern for their family, how their occupation influences their thoughts and feelings about death, and expressions of inability or unwillingness to think of their death. Expressions of fear of death, and feelings of anxiety on thinking of death provide qualitative evidence that awareness of death causes distress in a population with frequent exposure to traumatic experiences. Expressions of concern for families and contributions in response to MS prompt are consistent with prior theory and research that 
heightened awareness of death causes an increase in generative concern (Erikson 1963/1998; McAdams \& de St. Aubin, 1992; Maxfield et al., 2014a).

To our knowledge, even though the MS prompts we used have been used in hundreds of studies, no research has analyzed the content of participants' responses to mortality salience prompts. We believe this area to be fertile ground for research, as it gives insight into the thoughts and feelings that death arouses in people.

\section{Limitations}

Above, we identified possible ways participants of the control condition were also made aware of death, potentially spoiling DTA results. Our finding of a significant positive correlation between PTSD symptoms and DTA in both the MS and the control condition was inconsistent with previous ABDT research which shows equivocal DTA across levels of PTSD severity in control conditions or even a negative relationship between PTSD severity and DTA (Edmondson et al., 2011; Chatard et al., 2012). Without finding similar insignificant effects of PTSD symptoms on DTA in the control condition, we cannot know if the relation between PTSD symptoms and DTA is due to a disruption in death-denying functioning, or if persons with higher levels of trauma simply have generally higher activation of death thoughts due to exposure to trauma.

The present research used a word completion task to measure death-thought accessibility. Cognitive activation of death as measured by the DTA word completion task is not the same as death-anxiety. It is possible that disruption in death-anxiety buffering occurs, not primarily at the level of suppressing cognitive activation of death thoughts, but in suppressing negative affect and physiological arousal in response to 
cognitive activation of death. Anxiety buffering dysfunction may be better measured as a relation between PTSD symptoms and greater emotional and physiological reactivity to awareness of death, as compared to other distressing thoughts. Negative affect and physiological responses can be measured in a greater variety of ways than DTA and are promising direction for future research.

\section{Summary}

In our models, PTSD symptoms moderately predicted the anxiety buffer variable. While this relation may indicate the protective effects of the buffer variables, the relationship is likely bidirectional with trauma causing social withdrawal, lowering selfesteem, and less felt meaning in life. Cognitive-existential theories such as shattered assumptions theory and the meaning-making model predict traumatic experiences to decrease one's felt meaning in life, self-esteem, and interpersonal connectedness (JanoffBulman, 1992; Park et al., 2012). With only evidence of small effects of anxiety buffer variables on DTA following mortality salience, the present research indicates it is likely the anxiety buffer variables are primarily related to lower levels of posttraumatic stress in ways other than denying death. These anxiety buffer variables have previously been found to relate both to resiliency to trauma (Aiena et al., 2016; Alim et al., 2008), and posttraumatic growth (Bellizzi, 2004) and are generally considered positive mental health factors. Whether by preventing the development of PTSD or by helping increase meaning in life, self-esteem and social support, it appears that increasing care for others and things outside of oneself may be a promising way of caring for one's mental health. 


\section{REFERENCES}

American Psychiatric Association. (2013). Diagnostic and statistical manual of mental disorders (DSM-5) (5th ed.). Arlington, VA: American Psychiatric Publishing. doi:10.1176/appi.books.9780890425596

Abdollahi, A., Pyszczynski, T., Maxfield, M., \& Luszczynska, A. (2011). Posttraumatic stress reactions as a disruption in anxiety-buffer functioning: Dissociation and responses to mortality salience as predictors of severity of posttraumatic symptoms. Psychological Trauma: Theory, Research, Practice, And Policy, 3(4), 329-341. doi:10.1037/a0021084

Aiena, B. J., Buchanan, E. M., Smith, C. V., \& Schulenberg, S. E. (2016). Meaning, resilience, and traumatic stress after the Deepwater Horizon oil spill: A study of Mississippi coastal residents seeking mental health services. Journal Of Clinical Psychology, 72(12), 1264-1278. doi:10.1002/jclp.22232

Alim, T. N., Feder, A., Graves, R. E., Wang, Y., Weaver, J., Westphal, M., \& ... Charney, D. S. (2008). Trauma, resilience, and recovery in a high-risk African-American population. American Journal Of Psychiatry, 165(12), 1566-1575. doi:10.1176/appi.ajp.2008.07121939

Armstrong, D., Shakespeare-Finch, J., \& Shochet, I. (2013). Predicting post-traumatic growth and post-traumatic stress in firefighters. Australian Journal Of Psychology, 66(1), 38-46. doi:10.1111/ajpy.12032

Bailey, W. T. (1992). Psychosocial development in men: Generativity and involvement with young children. Psychological Reports, 71(7), 929-930. doi:10.2466/pr0.71.7.929-930

Bailey, W. T. (1994). Psychosocial development in women: Generativity. Psychological Reports, 74(1), 286. doi:10.2466/pr0.1994.74.1.286

Bellizzi, K. M. (2004). Expressions of generativity and posttraumatic growth in adult cancer survivors. International Journal Of Aging \& Human Development, 58(4), 267-287. doi:10.2190/dc07-cpvw-4uve-5gk0

Berger, W., Coutinho, E. F., Figueira, I., Marques-Portella, C., Luz, M. P., Neylan, T. C., \& ... Mendlowicz, M. V. (2011). Rescuers at risk: A systematic review and metaregression analysis of the worldwide current prevalence and correlates of PTSD in rescue workers. Social Psychiatry And Psychiatric Epidemiology, 47(6), 10011011. doi:10.1007/s00127-011-0408-2 
Burke, B. L., Martens, A., \& Faucher, E. H. (2010). Two decades of terror management theory: A meta-analysis of mortality salience research. Personality And Social Psychology Review, 14(2), 155-195. doi:10.1177/1088868309352321

Busch, H., \& Hofer, J. (2012). Self-regulation and milestones of adult development: Intimacy and generativity. Developmental Psychology, 48(1), 282-293. doi:10.1037/a0025521

Canty-Mitchell, J. \& Zimet, G.D. (2000). Psychometric properties of the multidimensional scale of perceived social support in urban adolescents. American Journal of Community Psychology, 28, 391-400. doi:10.1023/a:1005109522457

Chatard, A., Pyszczynski, T., Arndt, J., Selimbegović, L., Konan, P. N., \& Van der Linden, M. (2012). Extent of trauma exposure and PTSD symptom severity as predictors of anxiety-buffer functioning. Psychological Trauma: Theory, Research, Practice, And Policy, 4(1), 47-55. doi:10.1037/a0021085

Cole, E. R., \& Stewart, A. J. (1996). Meanings of political participation among Black and White women: Political identity and social responsibility. Journal Of Personality And Social Psychology, 71(1), 130-140. doi:10.1037/0022-3514.71.1.130

de St. Aubin, E., McAdams, D. P., \& Kim, T.-C. (Eds.). (2004). The generative society: Caring for future generations. Washington, DC: American Psychological Association. doi:10.1037/10622-000

Del Ben, K. S., Scotti, J. R., Chen, Y., \& Fortson, B. L. (2006). Prevalence of posttraumatic stress disorder symptoms in firefighters. Work \& Stress, 20(1), 37 48. doi:10.1080/02678370600679512

Donnelly, E., \& Siebert, D. (2009). Occupational risk factors in the Emergency Medical Services. Prehospital and Disaster Medicine, 24(5), 422-429. doi:10.1017/S1049023X00007251

Edmondson, D., Chaudoir, S. R., Mills, M. A., Park, C. L., Holub, J., \& Bartkowiak, J. M. (2011). From shattered assumptions to weakened worldviews: Trauma symptoms signal anxiety buffer disruption. Journal Of Loss And Trauma, 16(4), 358-385. doi:10.1080/15325024.2011.572030

Einolf, C. J. (2014). Stability and change in generative concern: Evidence from a longitudinal survey. Journal Of Research In Personality, 51, 54-61. doi:10.1016/j.jrp.2014.04.003

Erikson, E. H. (1963/1998). The life cycle completed. New York, NY: W. W. Norton \& Company. 
Farnsworth, J. K., \& Sewell, K. W. (2011). Fear of emotion as a moderator between PTSD and firefighter social interactions. Journal Of Traumatic Stress, 24(4), 444450. doi:10.1002/jts. 20657

Frankl, V. E., (1956/2006). Man's search for meaning. Boston, MA: Beacon Press.

Gauci, M. A., \& MacDonald, D. A. (2012). Confirmatory factor analysis of the posttraumatic stress disorder checklist. Journal Of Aggression, Maltreatment \& Trauma, 21(3), 321-330. doi:10.1080/10926771.2012.665429

Greenberg, J., Pyszczynski, T., Solomon, S., Simon, L., \& Breus, M. (1994). Role of consciousness and accessibility of death-related thoughts in mortality salience effects. Journal Of Personality \& Social Psychology, 67(4), 627-637. doi:10.1037/0022-3514.67.4.627

Hamama-Raz, Y., Mahat-Shamir, M., Pitcho-Prelorentzos, S., Zaken, A., David, U. Y., Ben-Ezra, M., \& Bergman, Y. S. (2016). The link between death anxiety and post-traumatic symptomatology during terror: Direct links and possible moderators. Psychiatry Research, 245, 379-386. doi:10.1016/j.psychres.2016.08.059

Hart, H. M., McAdams, D. P., Hirsch, B. J., \& Bauer, J. J. (2001). Generativity and social involvement among African Americans and White adults. Journal Of Research In Personality, 35(2), 208-230. doi:10.1006/jrpe.2001.2318

Hayes, J., Schimel, J., Faucher, E. H., \& Arndt, J. (2010). A theoretical and empirical review of the death-thought accessibility concept in terror management research. Psychological Bulletin, 136(5), 699-739. doi:10. 1037/a0020524

Heintzelman, S. J., Trent, J., \& King, L. A. (2016). How would the self be remembered? Evidence for posthumous self-verification. Journal Of Research In Personality, 61, 1-10. doi:10.1016/j.jrp.2015.12.004

Hu, L., \& Bentler, P. M. (1999). Cutoff criteria for fit indexes in covariance structure analysis: Conventional criteria versus new alternatives. Structural Equation Modeling: A Multidisciplinary Journal, 6(1), 1-55. doi:10.1080/10705519909540118

Iverach, L., Menzies, R. G., \& Menzies, R. E. (2014). Death anxiety and its role in psychopathology: Reviewing the status of a transdiagnostic construct. Clinical Psychology Review, 34(7), 580-593. doi:10.1016/j.cpr.2014.09.002

Janoff-Bulman, R. (1992). Shattered assumptions: Towards a new psychology of trauma. New York, NY: Free Press. 
Janoff-Bulman, R., \& McPherson Frantz, C. (1997). The impact of trauma on meaning: From meaningless world to meaningful life. In M. J. Power \& C. R. Brewin (Eds.), The transformation of meaning in psychological therapies: Integrating theory and practice (pp. 91-106). Hoboken, NJ: John Wiley.

Juhl, J., \& Routledge, C. (2016). Putting the terror in terror management theory. Current Directions In Psychological Science, 25(2), 99-103. doi: $10.1177 / 0963721415625218$

Kesebir, P., Luszczynska, A., Pyszczynski, T., \& Benight, C. (2011). Posttraumatic stress disorder involves disrupted anxiety-buffer mechanisms. Journal Of Social And Clinical Psychology, 30(8), 819-841. doi:10.1521/jscp.2011.30.8.819

Kruger, D., \& Swanepoel, M. (2017). Gluing the pieces together: Female adolescents' construction of meaning through digital metaphoric imagery in trauma therapy. Arts In Psychotherapy, 54, 92-104. doi:10.1016/j.aip.2017.04.011

Lambert, A. J., Eadeh, F. R., Peak, S. A., Scherer, L. D., Schott, J. P., \& Slochower, J. M. (2014). Toward a greater understanding of the emotional dynamics of the mortality salience manipulation: Revisiting the "affect-free" claim of terror management research. Journal Of Personality \& Social Psychology, 106(5), $655-$ 678. doi:10.1037/a0036353

Lang, A. J., \& Stein, M. B. (2005). An abbreviated PTSD checklist for use as a screening instrument in primary care. Behaviour Research \& Therapy, 43(5), 585-594. doi:10.1016/j.brat.2004.04.005

Lang, A. J., Wilkins, K., Roy-Byrne, P. P., Golinelli, D., Chavira, D., Sherbourne, C., \& ... Stein, M. B. (2012). Abbreviated PTSD Checklist (PCL) as a guide to clinical response. General Hospital Psychiatry, 34(4), 332-338. doi:10.1016/j.genhosppsych.2012.02.003

Larner, B., \& Blow, A. (2011). A model of meaning-making coping and growth in combat veterans. Review of General Psychology, 15(3), 187-197. doi: $10.1037 / \mathrm{a} 0024810$

Lawford, H. L., \& Ramey, H. L. (2015). 'Now I know I can make a difference': Generativity and activity engagement as predictors of meaning making in adolescents and emerging adults. Developmental Psychology, 51(10), 1395-1406. doi:10.1037/dev0000034

Lilly, M. M., Valdez, C. E., \& Graham-Bermann, S. A. (2011). The mediating effect of world assumptions on the relationship between trauma exposure and depression. Journal Of Interpersonal Violence, 26(12), 2499-2516. doi: $10.1177 / 088626051038303$ 
Major, R. J., Whelton, W. J., Schimel, J., \& Sharpe, D. (2016). Older adults and the fear of death: The protective function of generativity. Canadian Journal On Aging, 35(2), 261-272. doi:10.1017/s0714980816000143

Marmar, C. R., McCaslin, S. E., Metzler, T. J., Best, S., Weiss, D. S., Fagan, J., \& ... Neylan, T. (2006). Predictors of posttraumatic stress in police and other first responders. Annals Of The New York Academy Of Sciences, 1071(1), 1-18. doi:10.1196/annals.1364.001

Martz, E. (2004). Death anxiety as a predictor of posttraumatic stress levels among individuals with spinal cord injuries. Death Studies, 28(1), 1-17. doi:10.1080/07481180490249201

Maxfield, M., Greenberg, J., Pyszczynski, T., Weise, D. R., Kosloff, S., Soenke, M., \& ... Blatter, J. (2014a). Increases in generative concern among older adults following reminders of mortality. The International Journal Of Aging \& Human Development, 79(1), 1-21. doi:10.2190/ag.79.1.a

Maxfield, M., John, S., \& Pyszczynski, T. (2014b). A Terror management perspective on the role of death-related anxiety in psychological dysfunction. Humanistic Psychologist, 42(1), 35-53. doi:10.1080/08873267.2012.732155

McAdams, D. P. (1985). Power, intimacy, and the life story: Personological inquiries into identity. New York, NY: Guilford Press.

McAdams, D. P., \& de St. Aubin, E. (1992). A theory of generativity and its assessment through self-report, behavioral acts, and narrative themes in autobiography. Journal Of Personality And Social Psychology, 62(6), 1003-1015. doi:10.1037/0022-3514.62.6.1003

McAdams, D. P., Hart, H. M., \& Maruna, S. (1998). The anatomy of generativity. In D. P. McAdams, E. de St. Aubin, D. P. McAdams, \& E. de St. Aubin (Eds.), Generativity and adult development: How and why we care for the next generation (pp. 7-43). Washington, DC: American Psychological Association. doi:10.1037/10288-001

Morselli, D., \& Passini, S. (2015). Measuring prosocial attitudes for future generations: The social generativity scale. Journal of Adult Development, 22(3), 173-182. doi:10.1007/s10804-015-9210-9

Osman, A., Lamis, D. A., Freedenthal, S., Gutierrez, P. M., \& McNaughton-Cassill, M. (2014). The multidimensional scale of perceived social support: Analyses of internal reliability, measurement invariance, and correlates across gender. Journal Of Personality Assessment, 96(1), 103-112. doi:10.1080/00223891.2013.838170 
Ozer, E. J., Best, S. R., Lipsey, T. L., \& Weiss, D. S. (2003). Predictors of posttraumatic stress disorder and symptoms in adults: A meta-analysis. Psychological Bulletin, 129(1), 52-73. doi:10.1037/0033-2909.129.1.52

Ozer, E. J., \& Weiss, D. S. (2004). Who develops posttraumatic stress disorder?. Current Directions In Psychological Science, 13(4), 169-172. doi:10.1111/j.09637214.2004.00300.x

Park, C. L. (2013). Trauma and meaning making: Converging conceptualizations and emerging evidence. In J. Hicks \& C. Routledge (Eds.), The experience of meaning in life (pp 61-76). Dordrecht, Germany: Springer. doi:10.1007/978-94-007-65276 -5

Park, C. L., \& Ai, A. L. (2006). Meaning making and growth: New directions for research on survivors of trauma. Journal Of Loss And Trauma, 11(5), 389-407. doi:10.1080/15325020600685295

Park, C. L., \& Gutierrez, I. A. (2013). Global and situational meanings in the context of trauma: Relations with psychological well-being. Counselling Psychology Quarterly, 26(1), 8-25. doi:10.1080/09515070.2012.727547

Park, C. L., Mills, M. A., \& Edmondson, D. (2012). PTSD as meaning violation: Testing a cognitive worldview perspective. Psychological Trauma: Theory, Research, Practice, And Policy, 4(1), 66-73. doi:10.1037/a0018792

Peterson, B. E., Smirles, K. A., \& Wentworth, P. A. (1997). Generativity and authoritarianism: Implications for personality, political involvement, and parenting. Journal Of Personality \& Social Psychology, 72(5), 1202-1216. doi:10.1037/0022-3514.72.5.1202

Pyszczynski, T., \& Kesebir, P. (2011). Anxiety buffer disruption theory: A terror management account of posttraumatic stress disorder. Anxiety, Stress \& Coping: An International Journal, 24(1), 3-26. doi:10.1080/10615806.2010.517524

Pyszczynski, T., \& Taylor, J. (2016). When the buffer breaks: Disrupted terror management in posttraumatic stress disorder. Current Directions In Psychological Science, 25(4), 286-290. doi:10.1177/0963721416645537

Robins, R. W., Hendin, H. M., \& Trzesniewski, K. H. (2001). Measuring global selfesteem: Construct validation of a single-item measure and the Rosenberg selfesteem scale. Personality and Social Psychology Bulletin, 27, 151-161. doi: $10.1177 / 0146167201272002$

Ron, P. (2015) It's not their war: The impact of military operation on Philippine migrant care workers for elderly people in Israel. Clinical Interventions in Aging, 10, 1053-1061. doi:10.2147/cia.s77886 
Rosseel, Yves (2012). lavaan: An R package for structural equation modeling. Journal of Statistical Software, 48(2), 1-36. doi: 10.18637/jss.v048.i02

Schuler, E. R., \& Boals, A. (2016). Shattering world assumptions: A prospective view of the impact of adverse events on world assumptions. Psychological Trauma: Theory, Research, Practice, And Policy, 8(3), 259-266. doi:10.1037/tra0000073

Singer, J. A., King, L. A., Green, M. C., \& Barr, S. C. (2002). Personal identity and civic responsibility: 'Rising to the occasion' narratives and generativity in community action student interns. Journal Of Social Issues, 58(3), 535556. doi:10.1111/1540-4560.00275

Solomon, S., Greenberg, J., \& Pyszczynski, T. A. (2015). The worm at the core: On the role of death in life. New York, NY: Random House.

Steger, M. F., Frazier, P., Oishi, S., \& Kaler, M. (2006). The meaning in life questionnaire: Assessing the presence of and search for meaning in life. Journal Of Counseling Psychology, 53(1), 80-93. doi:10.1037/0022-0167.53.1.80

Steinman, C. T., \& Updegraff, J. A. (2015). Delay and death-thought accessibility. Personality and Social Psychology Bulletin, 41(12), 1682-1696. doi:10.1177/0146167215607843

Tabachnick, B. G., \& Fidell, L. S. (2007). Using multivariate statistics. Boston, MA: Pearson/Allyn \& Bacon.

van Buuren, S., Groothuis-Oudshoorn, K., (2011). mice: Multivariate imputation by chained equations in R. Journal of Statistical Software, 45(3), 1-67. doi: $10.18637 /$ jss.v045.i03

Weathers, F., Litz, B., Herman, D., Huska, J., \& Keane, T. (1993, October). The PTSD Checklist (PCL): Reliability, validity, and diagnostic utility. Paper presented at the annual meeting of the International Society for Traumatic Stress Studies, San Antonio, TX.

Weinberg, M. (2013). The bidirectional dyadic association between tendency to forgive, self-esteem, social support, and PTSD symptoms among terror-attack survivors and their spouses. Journal Of Traumatic Stress, 26(6), 744-752. doi:10.1002/jts.21864

Weiss D.S., \& Ozer E.J. (2006). Predicting who will develop posttraumatic stress disorder. In: G. Young, K. Nicholson, \& A.W. Kane (Eds.), Psychological knowledge in court (pp 85-96). Boston, MA: Springer. doi: 10.1007/0-387-256105_5 
Zhou, X., Wu, X., \& Zhen, R. (2018). Self-esteem and hope mediate the relations between social support and post-traumatic stress disorder and growth in adolescents following the Ya'an earthquake. Anxiety, Stress \& Coping, 31(1), 3245. doi:10.1080/10615806.2017.1374376

Zimet, G.D., Dahlem, N.W., Zimet, S.G. \& Farley, G.K. (1988). The multidimensional scale of perceived social support. Journal of Personality Assessment, 52(1), 3041. doi:10.1207/s15327752jpa5201_2

Zimet, G.D., Powell, S.S., Farley, G.K., Werkman, S. \& Berkoff, K.A. (1990). Psychometric characteristics of the multidimensional scale of perceived social support. Journal of Personality Assessment, 55, 610-617. doi:10.1207/s15327752jpa5503\&4_17 
Table 1.

Means and standard deviations of study variables

\begin{tabular}{lccc}
\hline Variable & $\begin{array}{c}\text { Overall } \\
M(S D)\end{array}$ & $\begin{array}{c}\text { Control } \\
M(S D)\end{array}$ & $\begin{array}{c}\text { Mortality Salience } \\
M(S D)\end{array}$ \\
\hline Abbreviated PCL-C & $14.57(5.51)$ & $14.21(5.33)$ & $15.18(5.71)$ \\
Generativity & $36.83(8.98)$ & $37.39(8.82)$ & $36.12(9.42)$ \\
Present Meaning in Life & $26.02(6.20)$ & $26.49(6.08)$ & $25.43(6.41)$ \\
Search for Meaning in Life & $22.19(7.18)$ & $22.10(7.31)$ & $22.30(7.14)$ \\
Social-Support & $5.14(1.28)$ & $5.23(1.36)$ & $5.03(1.20)$ \\
Self-Esteem & $4.33(2.15)$ & $4.40(2.18)$ & $4.24(2.16)$ \\
DTA & $2.05(1.19)$ & $2.03(1.17)$ & $2.07(1.20)$ \\
\hline
\end{tabular}


Table 2.

Correlation of PTSD symptoms, anxiety buffer variables, and DTA

\begin{tabular}{lcccccc}
\hline Variable & 1 & 2 & 3 & 4 & 5 & 6 \\
\hline 1. Abbreviated PCL-C & - & & & & & \\
2. Generativity & $-.28^{* * *}$ & - & & & & \\
3. Present Meaning in Life & $-.34 * * *$ & $.60 * * *$ & - & & & \\
4. Search for Meaning in Life & $.20^{* * *}$ & $-.14^{* * *}$ & $-.37 * * *$ & - & & \\
5. Social-Support & $-.31 * * *$ & $.43 * * *$ & $.40^{* * *}$ & $-.15^{* * *}$ & - & \\
6. Self-Esteem & $-.35^{* * *}$ & $.47 * * *$ & $.52 * * *$ & $-.26 * * *$ & $.31 * * *$ & - \\
7. DTA & $.15 * * *$ & $-.08^{*}$ & $-.11 * *$ & .07 & $-.12 * *$ & $-.12 * *$
\end{tabular}

Note. $*$ indicates $p<.05, * *$ indicates $p<.01, * * *$ indicates $p<.001$ 
Table 3.

Correlation of variables in control condition

\begin{tabular}{lcccccc}
\hline Variable & 1 & 2 & 3 & 4 & 5 & 6 \\
\hline 1. Abbreviated PCL-C & - & & & & & \\
2. Generativity & $-.29 * *$ & - & & & & \\
3. Present Meaning in Life & $-.39 * * *$ & $.59 * * *$ & - & & & \\
4. Search for Meaning in Life & $.20^{* * *}$ & $-.12^{*}$ & $-.38^{* * *}$ & - & & \\
5. Social-Support & $-.30^{* * *}$ & $.41^{* * *}$ & $.34^{* * *}$ & $-.14^{* *}$ & - & \\
6. Self-Esteem & $-.35^{* * *}$ & $.50^{* * *}$ & $.57^{* * *}$ & $-.26^{* * *}$ & $.27 * * *$ & - \\
7. DTA & $.18^{* *}$ & -.06 & -.09 & .09 & $-.12 *$ & -.11 \\
\hline
\end{tabular}

Note. $*$ indicates $p<.05, * *$ indicates $p<.01, * * *$ indicates $p<.001$ 
Table 4.

Correlation of variables in mortality salience condition

\begin{tabular}{lcccccc}
\hline Variable & 1 & 2 & 3 & 4 & 5 & 6 \\
\hline 1. Abbreviated PCL-C & - & & & & & \\
2. Generativity & $-.28^{* * *}$ & - & & & & \\
3. Present Meaning in Life & $-.31^{* * *}$ & $.64^{* * *}$ & - & & & \\
4. Search for Meaning in Life & $.21^{* * *}$ & $-.18^{* *}$ & $-.37^{* * *}$ & - & & \\
5. Social-Support & $-.33^{* * *}$ & $.46^{* * *}$ & $.46^{* * *}$ & $-.14^{* *}$ & - & \\
6. Self-Esteem & $-.34^{* * *}$ & $.46^{* * *}$ & $.51 * * *$ & $-.27^{* * *}$ & $.36^{* * *}$ & - \\
7. DTA & $.13^{*}$ & -.11 & $-.12^{*}$ & .04 & -.11 & $-.14^{*}$ \\
\hline
\end{tabular}

Note. $*$ indicates $p<.05, * *$ indicates $p<.01, * * *$ indicates $p<.001$ 
Table 5.

Parameter Estimates for Control Condition

\begin{tabular}{|c|c|c|c|c|c|c|c|c|}
\hline Variable & Estimate & Est. & $S E$ & LL & UL & $\beta$ & $Z$ & $p$ \\
\hline \multirow[t]{4}{*}{ Buffer } & Generativity & 1 & 0 & 1 & 1 & .753 & NA & NA \\
\hline & Present Meaning & 0.712 & 0.061 & 0.592 & 0.833 & .794 & 11.600 & $<.001$ \\
\hline & Self-Esteem & 0.224 & 0.021 & 0.184 & 0.264 & .707 & 10.87 & $<.001$ \\
\hline & Social Support & 0.087 & 0.013 & 0.063 & 0.112 & .443 & 6.955 & $<.001$ \\
\hline \multirow[t]{2}{*}{ DTA } & Buffer & -0.008 & 0.013 & -0.033 & 0.016 & -.048 & -0.663 & .507 \\
\hline & PTSD Symptoms & 0.036 & 0.015 & 0.007 & 0.065 & .159 & 2.444 & .015 \\
\hline Buffer & PTSD Symptoms & -0.587 & 0.082 & -0.748 & -0.425 & -.449 & -7.126 & $<.001$ \\
\hline Generativity & Variance & 34.289 & 4.072 & 26.308 & 42.269 & .433 & 8.421 & $<.001$ \\
\hline Present Meaning & Variance & 13.398 & 1.828 & 9.815 & 16.982 & .370 & 7.328 & $<.001$ \\
\hline Self-Esteem & Variance & 2.251 & 0.24 & 1.781 & 2.721 & .500 & 9.389 & $<.001$ \\
\hline Social Support & Variance & 1.401 & 0.121 & 1.165 & 1.638 & .803 & 11.613 & $<.001$ \\
\hline DTA & Variance & 1.326 & 0.108 & 1.114 & 1.538 & .966 & 12.281 & $<.001$ \\
\hline Buffer & Variance & 35.894 & 5.339 & 25.429 & 46.359 & .798 & 6.722 & $<.001$ \\
\hline PTSD Symptoms & Variance & 26.370 & 0 & 26.370 & 26.370 & 1 & NA & NA \\
\hline Indirect Effect & & 0.005 & 0.007 & -0.010 & 0.019 & .021 & 0.661 & .509 \\
\hline
\end{tabular}


Table 6.

Parameter Estimates for Mortality Salience Condition

\begin{tabular}{llrrrrrrrr}
\hline Variable & Estimate & Est. & $S E$ & LL & UL & $\beta$ & $Z$ & $p$ \\
\hline Buffer & Generativity & 1 & 0 & 1 & 1 & .752 & NA & NA \\
& Present Meaning & 0.746 & 0.066 & 0.616 & 0.875 & .805 & 11.274 & $<.001$ \\
& Self-Esteem & 0.193 & 0.021 & 0.152 & 0.233 & .617 & 9.388 & $<.001$ \\
& Social Support & 0.100 & 0.011 & 0.078 & 0.122 & .575 & 8.778 & $<.001$ \\
& Buffer & -0.023 & 0.013 & -0.048 & 0.002 & -.132 & -1.823 & .068 \\
DTA & PTSD Symptoms & 0.015 & 0.014 & 0.012 & 0.043 & .072 & 1.108 & .268 \\
& PTSD Symptoms & -0.511 & 0.080 & -0.667 & -0.355 & -.415 & -6.428 & $<.001$ \\
Buffer & Variance & 36.768 & 4.499 & 27.951 & 45.586 & .434 & 8.173 & .575 \\
Generativity & Variance & 14.464 & 2.145 & 10.260 & 18.669 & .352 & 6.742 & $<.001$ \\
Present Meaning & & 2.890 & 0.280 & 2.341 & 3.439 & .619 & 10.318 & $<.001$ \\
Self-Esteem & Variance & & & & & & & \\
Social Support & Variance & 0.967 & 0.091 & 0.789 & 1.144 & .669 & 10.668 & $<.001$ \\
DTA & Variance & 1.393 & 0.116 & 1.165 & 1.620 & .969 & 11.991 & $<.001$ \\
Buffer & Variance & 39.666 & 6.029 & 27.849 & 51.482 & .827 & 6.579 & $<.001$ \\
PTSD Symptoms & Variance & 31.660 & 0 & 31.660 & 31.660 & 1 & NA & NA \\
Indirect Effect & & 0.012 & 0.007 & -0.010 & 0.025 & .055 & 1.770 & .077 \\
& & & & & & & & &
\end{tabular}




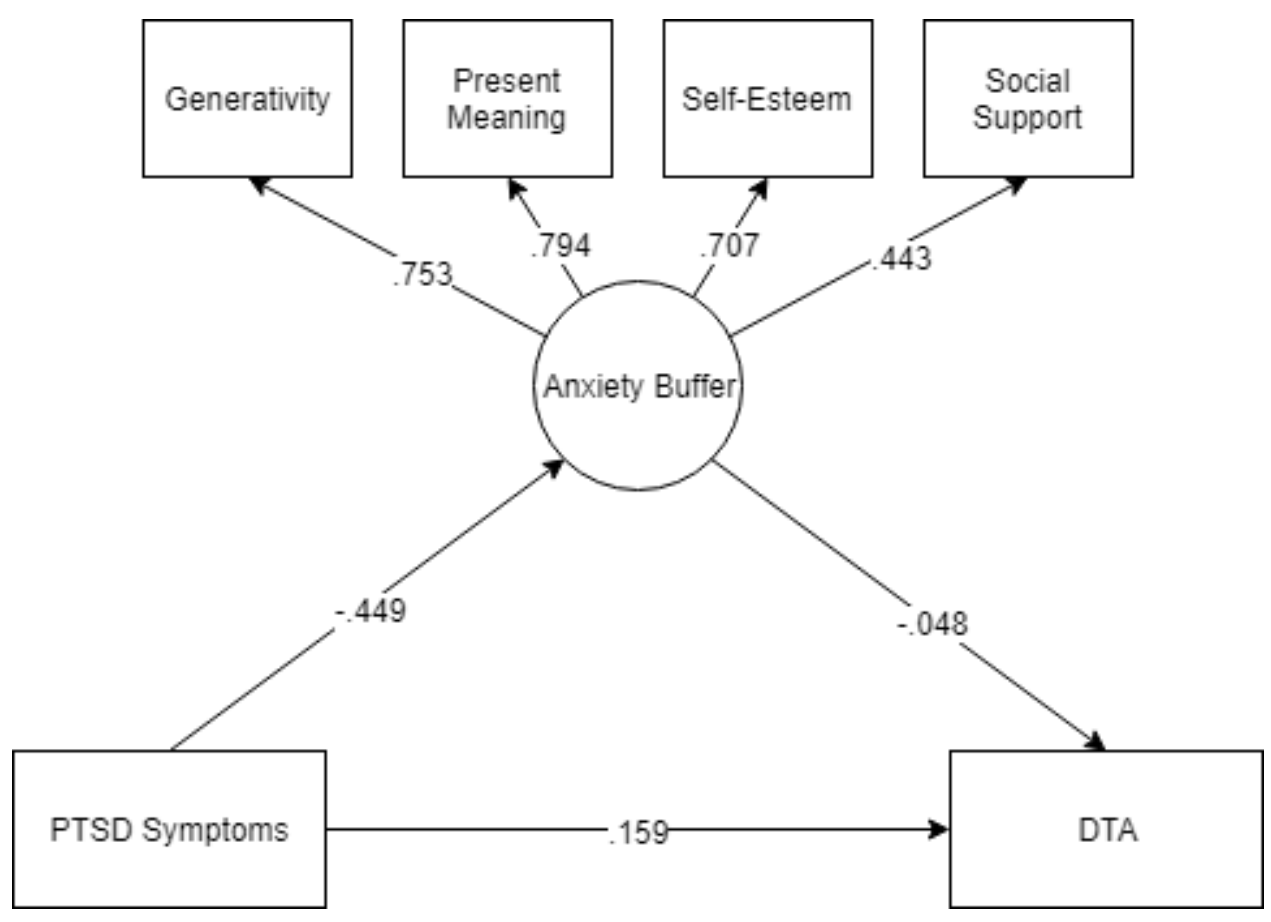

Figure 1. Path model of variables in control condition displaying standardized coefficients. DTA $=$ death-thought accessibility. Indirect effect $=.021, p=.509$. 


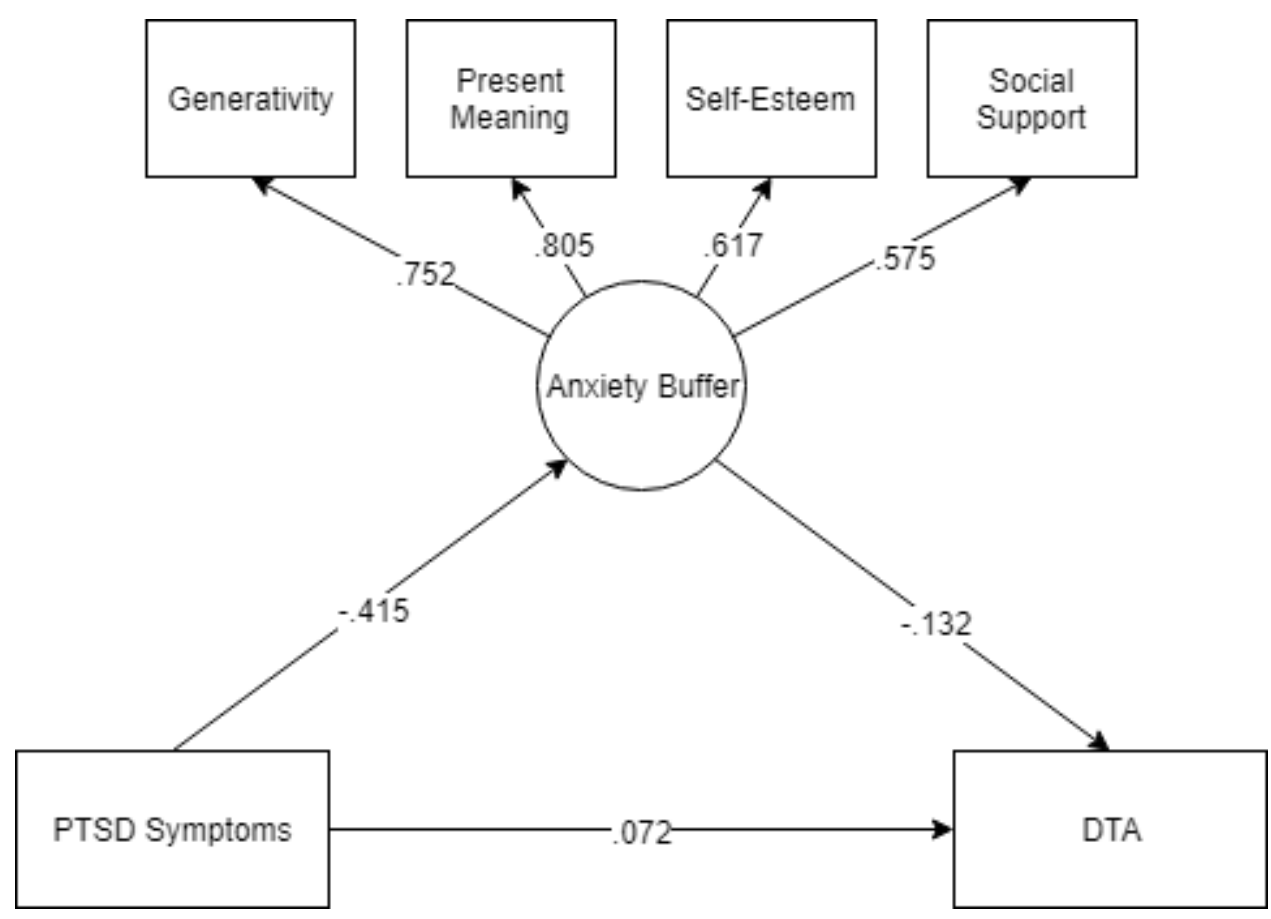

Figure 2. Path model of variables in mortality salience condition displaying standardized coefficients. DTA = death-thought accessibility. Indirect effect $=.055, p=.077$. 


\section{APPENDIX}

\section{Human Subjects IRB Approval}

IRB \#: IRB-FY2017-754

Title: David's Thesis

Creation Date: 6-14-2017

End Date: 11-12-2018

Status: Approved

Principal Investigator: Erin Buchanan

Review Board: MSU

Sponsor:

\section{Study History}

Submission Type Initial

Review Type Expedited

Decision Approved

Key Study Contacts

\begin{tabular}{lll}
\hline Member Erin Buchanan & Role Principal Investigator & $\begin{array}{l}\text { Contact } \\
\text { erinbuchanan@missouristate.edu }\end{array}$ \\
\hline Member David Herr & Role Primary Contact & $\begin{array}{l}\text { Contact } \\
\text { herr316@live.missouristate.edu }\end{array}$ \\
\hline Member David Herr & Role Investigator & $\begin{array}{l}\text { Contact } \\
\text { herr316@live.missouristate.edu }\end{array}$
\end{tabular}

